\title{
Solar System Exploration Augmented by In-Situ Resource Utilization: Mercury and Saturn Propulsion Investigations
}

\author{
Bryan Palaszewski \\ NASA John H. Glenn Research Center \\ Lewis Field \\ Cleveland, $\mathrm{OH} 44135$ \\ (216) 977-7493 Voice \\ (216) 433-5802 FAX \\ bryan.a.palaszewski@nasa.gov
}

Human and robotic missions to Mercury and Saturn are presented and analyzed with a range of propulsion options. Historical studies of space exploration, in-situ resource utilization (ISRU), and industrialization all point to the vastness of natural resources in the solar system. Advanced propulsion benefitted from these resources in many ways. While advanced propulsion systems were proposed in these historical studies, further investigation of nuclear options using high power nuclear thermal and nuclear pulse propulsion as well as advanced chemical propulsion can significantly enhance these scenarios. Updated analyses based on these historical visions will be presented. Nuclear thermal propulsion and ISRU enhanced chemical propulsion landers are assessed for Mercury missions. At Saturn, nuclear pulse propulsion with alternate propellant feed systems and Titan exploration with chemical propulsion options are discussed. Insitu resource utilization was found to be critical in making Mercury missions more amenable for human visits. At Saturn, refueling using local atmospheric mining was found to be difficult to impractical, while refueling the Saturn missions from Uranus was more practical and less complex.

Nomenclature

$\begin{array}{ll}\text { 3He } & \text { Helium } 3 \\ \text { 4He } & \text { Helium (or Helium 4) } \\ \text { AMOSS } & \text { Atmospheric mining in the outer solar system } \\ \text { ASC } & \text { Aerospacecraft (for atmospheric mining) } \\ \text { CC } & \text { Closed cycle } \\ \text { delta-V } & \text { Change in velocity }(\mathrm{km} / \mathrm{s}) \\ \text { GCR } & \text { Gas core rocket } \\ \text { GTOW } & \text { Gross Takeoff Weight } \\ \text { H2 } & \text { Hydrogen } \\ \text { He } & \text { Helium 4 } \\ \text { ITV } & \text { Interplanetary transfer vehicle } \\ \text { ISRU } & \text { In Situ Resource Utilization } \\ \text { Isp } & \text { Specific Impulse (s) } \\ \text { K } & \text { Kelvin } \\ \text { kWe } & \text { Kilowatts of electric power } \\ \text { LEO } & \text { Low Earth Orbit }\end{array}$

* Leader of Advanced Fuels, AIAA Associate Fellow 


$\begin{array}{ll}\text { MESSENGER } & \text { Mercury Space Surface ENvironment, GEochemistry, and Ranging } \\ \text { MT } & \text { Metric tons } \\ \text { MWe } & \text { Megawatt electric (power level) } \\ \text { NEP } & \text { Nuclear Electric Propulsion } \\ \text { NPP } & \text { Nuclear Pulse Propulsion } \\ \text { NTP } & \text { Nuclear Thermal Propulsion } \\ \text { NTR } & \text { Nuclear Thermal Rocket } \\ \text { OC } & \text { Open cycle } \\ \text { O2 } & \text { Oxygen } \\ \text { PPB } & \text { Parts per billion }\end{array}$

\section{Introduction}

Human and robotic missions have been planned for targets throughout the solar system. Both types of missions can benefit greatly from the resources available from the planets and /or their moons (Refs. 1-15). These benefits include water on many of the outer planet moons and large asteroids. With this water, oxygen / hydrogen rocket propulsion systems can be fueled, breathing oxygen can be extracted, and other life support functions (cooling fluids, etc.) can be facilitated. In addition, the atmospheres of many planets have ready reserves of gases for propellant production. Carbon dioxide on Mars can be separated into oxygen and carbon monoxide or, with small amounts of hydrogen and methane can be produced. The outer planets offer enormous amounts of energetic gases such as hydrogen, helium 3, methane, ethane, and ammonia. By using these in-situ resources, robotic precursor missions can double or triple their payloads to the surface and return double or triple the samples from the solar system targets. Without in-situ resource utilization (ISRU), solar system exploration will be exceedingly limited. For future large scale human missions, the possibilities of ISRU for human exploration and settlement offer the best opportunities for sustainability and success.

\section{Human Exploration Options}

In the 1950's, 1960's, 1970's, and 1980's, ambitious robotic and human mission were planned, spanning from Mercury to the outermost reaches of the solar system (Refs. 1-15). While investments in robotic missions have continued, human exploration of the solar system has awaited new invigorating steps. While lunar and Mars missions are in the early step-wise planning stages, many cost barriers have prevented their implementation. Future human missions to other destinations such as Mercury and Saturn will also require long-term investments. Currently, Mercury and Saturn have robotic missions returning invaluable data on those planets and their environs (Refs. 16 to 20). These data have provided insights that will ensure the success of future missions. With its proximity to the Sun, Mercury has extremely high temperatures and missions requires special high heat flux considerations for long-term human visits or bases. In contrast, temperatures at Saturn and its moons require designs for cryogenic environments.

\section{A. Mission targets}

The Mercury landing missions are focused on northern polar targets (Refs. 16, 17. And 18). Permanently shadowed craters in these northern polar regions on Mercury contain water ice (Ref. 16, 17, and 18). With this water ice, ISRU factories can produce the oxygen and hydrogen for ascent and descent lander propulsion and hydrogen for the return to Earth on the orbiting NTP vehicle.

The targets at Saturn are primarily its moons (Titan, Iapetus, etc.), its atmosphere, and its ring system (Refs. 19 and 20). Atmospheric mining in the outer solar system (AMOSS) has been assessed for Saturn missions. Due to the 
extreme atmospheric environmental conditions at Saturn, AMOSS operations there are not recommended. In addition, the delta- $\mathrm{V}$ to extract the propellants from the atmosphere and transport it to a moon or other location is quite prohibitive. Alternatively, performing AMOSS at Uranus and transporting the propellant to a Saturn target (Titan, etc.) has been assessed and is more practical than AMOSS at Saturn and greatly reduces the delta-V required, thus reducing the overall system complexity. Also, extracting propellants from the more-benign Uranus environment also improves vehicle safety.

\section{Human Space Vehicles and Missions}

Space vehicle engine performance, propulsion mass scaling and delta-V estimates were used to predict the LEO masses of both Mercury and Saturn exploration vehicles. LEO mass estimates for extremely high energy missions were assessed. Several ISRU options were investigated at Mercury and Saturn.

\section{A. Mercury Missions}

A human round trip mission to Mercury was assessed. The mission $\Delta \mathrm{V}$ values for the round trip Mercury missions were derived from the literature (Refs. 21 to 25). The highest $\Delta \mathrm{V}$ case was selected from this data: an Earth departure delta- $\mathrm{V}$ of $5.2 \mathrm{~km} / \mathrm{s}$, a Mercury arrival $\Delta \mathrm{V}$ of $10.9 \mathrm{~km} / \mathrm{s}$ and a Mercury departure $\Delta \mathrm{V}$ of $8.7 \mathrm{~km} / \mathrm{s}$ (Ref. 12). At Earth, a capsule enters the atmosphere to return the crew directly to Earth (Ref. 12). The capsule's mass is $4,350 \mathrm{~kg}$; the round trip time is 585 days with a 40 -day stay time at Mercury. In this case, the vehicle does not land on Mercury (Ref. 12). The LEO masses of both chemical propulsion and nuclear thermal propulsion vehicles were estimated. Figure 1 compares the LEO masses for 2 types of chemical propulsion systems (with the differing tankage mass assumptions noted below) and 2 nuclear thermal propulsion (NTP) systems. The interplanetary chemical propulsion systems used tankage dry mass coefficients of 3\% and 5\% of the total propellant mass in the tankage. In many cases, these dry masses may be deemed to be optimistically low; however, they allow some relative comparison of the chemical propulsion and the nuclear mission cases. The chemical propulsion transfer vehicles used 3 stages, while the NTP stages, with the higher dry mass coefficient, required 6 stages. With the NTP vehicles, each of the three large interplanetary maneuvers were split equally between the 2 stages for each of the three maneuvers.

The NTP vehicles' dry mass was 33\% of the propellant mass (Ref. 34). This is a more conservative assumption that was used in Ref. 32. In current NTP designs, an $\mathrm{I}_{\mathrm{sp}}$ of 900 seconds is nominally used. Somewhat lower $\mathrm{I}_{\mathrm{sp}}$ values were used for these missions: 800 and 850 seconds, respectively (Ref. 12). These lower $\mathrm{I}_{\mathrm{sp}}$ values were assumed given the high heat flux environment of Mercury and the degraded $\mathrm{I}_{\mathrm{sp}}$ values would reflect the added propellant used for propellant cooling and/or refrigeration. The chemical propulsion systems required between 17,150 MT and 31,230 MT to accomplish the mission. The NTP vehicles required approximately an order of magnitude less mass in LEO: 3,900 MT to 2,800 MT. Based on our prior analysis, the stage and lander mass was estimated with a mass scaling equation (Refs. 21 to 25 ).

$\mathrm{M}_{\text {dry,stage }}(\mathrm{kg})=\mathrm{M}_{\text {dry,coefficient }} \bullet \mathrm{M}_{\mathrm{p}}(\mathrm{kg})$

where:

$\mathrm{M}_{\text {dry,stage }}=$ the stage dry mass, including residual propellant $(\mathrm{kg})=$

$\mathrm{M}_{\mathrm{dry}, \text { coefficient }}=$ the $\mathrm{B}$ mass coefficient ( $\mathrm{kg}$ of tank mass $/ \mathrm{kg}$ of usable propellant mass)

$\mathrm{M}_{\mathrm{p}}=$ usable propellant mass $(\mathrm{kg})$ 
A Mercury landing vehicle mass was also estimated; the one-way $\Delta \mathrm{V}$ for the lander was $3.5 \mathrm{~km} / \mathrm{s}$. The ascent $\Delta \mathrm{V}$ was also $3.5 \mathrm{~km} / \mathrm{s}$ (Ref. 22). These $\Delta \mathrm{V}$ values accommodate approximately $19 \%$ for gravity losses for each maneuver; this gravity loss $\Delta \mathrm{V}$ is added to the orbital velocity for a $100 \mathrm{~km}$ orbit which is $2.945 \mathrm{~km} / \mathrm{s}$. The lander $\mathrm{I}_{\mathrm{sp}}$ was 480 seconds. The higher $\mathrm{I}_{\mathrm{sp}}$ was chosen for the lander as the engine used a higher engine expansion ratio than the interplanetary transfer vehicle. The smaller engine size would allow a higher expansion ratio, given the typical volume constraints for space vehicles. The dry mass coefficient was $20 \%$ of the total propellant load. While the Mercury missions will likely require more aggressive thermal control (propellant shielding, cooling, etc.), that thermal control system mass is accommodated in the payload mass of the vehicle. The payload delivered to the surface was $10 \mathrm{MT}$. Figure 2 compares the mass in LEO of a one-way lander and a round trip lander. The masses were approximately 140 MT for the round trip lander and 27 MT for the one-way lander. Thus, using ISRU on the surface of Mercury to replenish the lander's propellant would allow a savings of 113 MT on this mission. Additional analyses are needed to investigate the mass reductions for the interplanetary transfer vehicle to carry the lander to Mercury. Another option would be to carry 5 landers to Mercury rather than carry simply one lander; many more permanently shadowed craters could then be visited on one mission. The interplanetary vehicle carrying the 5 landers could be sent on a lower energy trajectory than the human flights, thus saving additional mass launched into LEO in the overall Mercury architecture.

Using Mercury resources to augment the human missions was investigated. An ISRU system's effects on reducing the LEO mass (see Table 1 for details of the NTP-1 and NTP-2) was analyzed. For the NTP-1 and NTP-2 systems, cases were computed where the Mercury departure $\Delta \mathrm{V}$ propellant was supplied at Mercury. The Mercury departure stages are brought from Earth with no propellant. Hydrogen would be produced from the water at the northern polar craters, and transported to orbit. For the NTP-1 case, 104 MT of hydrogen would be transported to orbit. With NTP-2, the propellant mass required in Mercury orbit is $90 \mathrm{MT}$. With the in-situ hydrogen production, the LEO mass of the NTP-1 case is reduced from 3,892 MT to 1,517 MT, as shown in Figure 1. Similar large LEO mass reductions are enabled for the NTP-2 system; using ISRU, the 2,793 MT LEO mass is reduced to 1,136 MT.

Table IV, V, and VI provide the mass summaries of the NTP-1 and NTP-2 options. The propellant masses and dry masses each stage are noted. The stage 5 and stage 6 propellant masses that would be fueled with Mercury hydrogen ISRU are highlighted. As part of the architecture, Mercury landers would carry the hydrogen needed for the return trip to orbit. For the NTP-1 missions 11 round trip lander flights are needed for refueling. With NTP-2, the round trip lander flights needed are reduced to approximately 10. These numbers of flights do not include any additional hydrogen that may be required for cryogenic chill down of the stages tankage and other propulsion components.

Table 1. Space Vehicle Dry Mass Coefficient and Rocket Engine Specific Impulse $\left(\mathrm{I}_{\mathrm{sp}}\right)$

\begin{tabular}{|l|c|c|}
\hline \multicolumn{1}{|c|}{ Technology } & $\mathbf{I}_{\text {sp }}$ (sec) & M $_{\text {dry,coefficient }}(\mathbf{k g} / \mathbf{k g}$ Mp) \\
\hline Chemical-1 & 450 & 0.03 \\
\hline Chemical-2 & 450 & 0.05 \\
\hline Chemical lander & 480 & 0.20 \\
\hline NTP-1 & 800 & 0.33 \\
\hline NTP-2 & 850 & 0.33 \\
\hline
\end{tabular}




\section{B. Mercury surface excursion planning}

While the temperature is quite comfortable for human habitation inside the permanently shadowed craters (PSC), excursions will be desirable to other locations. While the temperature can be quite high outside the PSC, short excursion will be possible. Robotic missions with cooling systems can persist for long periods in the sunlit areas. These explorers can provide data on the most attractive locations for sampling, and the need for human exploration. Cooling systems based on the heat pipe based design from MESSENGER can be effective (Ref. 22).

Hopping out of permanently shadowed craters for short periods will be desirable. Hopper spacecraft have been conceived for many planetary missions (Ref. 24). While the hoppers can be used for excursions outside the PSC, flights into the anti-Sun shadowed regions of the Mercury will allow for more extensive planet wide exploration (or in essence, wait until it is night time).

Placement of a propellant factory for oxygen and hydrogen production will be a serious issue. Table II provides a mass summary of 4 different propellant factory options. Co-locating the factory and the lander vehicles will likely be attractive from reducing the propellant tankage required for storage. In this case, the tankage of the lander is used for propellant storage. However, the larger tankage for cryogenic hydrogen storage (for the orbiting NTP vehicle, for Trans Earth Injection) may be placed away from the landing area, as the tankage may be partially buried in the cryogenic water ice in the PSC.

\section{Factory sizing}

One or more factories will be needed in the transportation system. At Mercury, the factories will created oxygen and hydrogen for the landers and hydrogen for the orbiting NTP vehicle. With the Saturn AMOSS, there is a gas separation and liquefaction system or factory on the ASC. Also needed will be one or 2 factories on the moon (Titan, etc.) for payload storage. One factory will created oxygen and hydrogen for moon lander propellants. Another may be needed to process the helium 3 (and other fusion fuels such as deuterium). The factory sizing was estimated by breaking down the factory into the planned components.

Table II lists the subsystems of the propellant factories. Several estimates were created, each reflecting a different level of propellant storage or complexity. The lowest mass factory used the lander propellant tanks as the primary propellant storage tankage. The more massive options used separate tankage to store the propellants.

The factory mass for nuclear fuel elements (physics packages, PPack) or nuclear fusion pellets was also estimated. As there are large uncertainties in the number of required processes, and complexities associated with low gravity processing of nuclear materials, three PPack factory masses were assessed.

\section{Factory results - propellants:}

The masses of the propellant factories were based on four design options: lightweight factory (all external storage and processing), heavy factory (also with external storage and processing), lightweight factory with propellants fed to the lander, and the super lightweight factory, using integral propellant storage on the lander (with no external lander propellant or fluid storage). A mass summary of the four cases is provided in Table II. The range of masses were from $7 \mathrm{MT}$ for the super lightweight case (using integral propellant storage on the lander) to $21 \mathrm{MT}$ for the heavy factory. While the super lightweight factory is very attractive, no propellant processing can be conducted while the lander is not located at the base. Therefore, the lightweight factory with the propellant fed to the lander is attractive. However, the heavy factory allows for longer term propellant production and storage away from the lander, and may be the most conservative option. 


\section{E. Factory results - PPack:}

Mass estimates for the physics package (PPack) factory were created. The largest unknowns of the PPack factory were parametrically assessed. These cases were named the light factory, heavy factory, and super heavy factory. Table III lists the major subsystems in the PPack factory. The biggest variable mass was 100, 500, and $1,000 \mathrm{MT}$, respectively, for the nuclear fuel processing. These systems were the most difficult to estimates and therefore a wide range of masses were considered. The other remaining factory masses were estimates based on past studies. The final masses of the PPack options were 161, 561, and 1061 MT. As the PPack is for accepting, storing and manipulating nuclear materials, specialized robotic system will be needed for accepting, storing, and reprocessing those materials into usable propellants.

The most important processes may indeed be the basing and emplacement of the propellant and PPack factories. The safe and reliable operation of the factory for decades will be necessary. Also, purification of the water and other gases will be critical. Typically, water is full of salts, as with the Earth's oceans. The same is true for any interplanetary moons' water supplies (Ref. 32 and 33). Using the propellants in chemical or electric propulsion systems and in the operations of the factories will necessitate their purification.

\section{F. Saturn mission studies and results}

Human Jupiter and Saturn mission analyses using nuclear pulse propulsion were conducted in the 1960's and 1970's (Ref. 13, 14, 15). Small nuclear devices (or bomblets) were detonated behind the vehicle and with a combination of 100's of nuclear devices, a massive pusher plate and shock absorbers, the vehicle is accelerated through the needed delta-V. The LEO masses for varying propulsion dry masses and total mission delta-V assumptions were estimated. These missions used propulsion mass scaling that may have been optimistic. Parametric variation of the dry mass was analyzed.

References 13, 14 and 15 provided the details from which the propulsion system mass scaling equations were derived. The A parameter of $358,000 \mathrm{~kg}$ is the mass of the pusher plate and associated shock absorbers for the 20-meter diameter system. The 20-meter diameter system design was used on the outer planet mission analyses conducted in Refs. 14 and 15. The Saturn and the Jupiter mission studies used the same set of propulsion mass scaling equations. The Saturn mission delta-V values were derived from Refs. 13, 14 and 15.

The mass scaling equation was:

$\operatorname{Mdry}(\mathrm{kg})=\mathrm{A}+\mathrm{B} \mathrm{Mp}$

where

Mdry $=$ Propulsion system dry mass including residual propellant $(\mathrm{kg})$

$\mathrm{Mp}=$ Usable propellant mass $(\mathrm{kg})$

$\mathrm{A}=$ fixed propulsion system mass $(\mathrm{kg})$

$\mathrm{B}=$ propellant mass dependent mass $(\mathrm{kg} / \mathrm{kg} \mathrm{Mp})$

The final set of mass scaling equations were:

M,dry $(\mathrm{kg})=358,000+0.01 \mathrm{Mp}$ 
Also the parameter $\mathrm{B}$ was also varied over a range of values: $\mathrm{B}=0.01,0.02,0.05$ and 0.10 . The NPP space vehicle Isp was 3,000 seconds. While a 3,150 second Isp was used in Ref. 13 and 14, the lower (and more conservative) 3,000 second value was used in later publications (Ref. 15).

Figures 3 and 4 provide the mass estimates for a series of Saturn missions over a range of mission delta-V. Based on the work of Ref. 13, 14, 15, and 26 for human Jupiter and Saturn missions, a range of mission delta-V from $60 \mathrm{~km} / \mathrm{s}$ to $120 \mathrm{~km} / \mathrm{s}$ was used in the calculations. While the highest delta$\mathrm{V}$ values may represent impractically high LEO masses for some space missions, they are presented for comparison and completeness. The same overall mission payload masses were used for human Jupiter and Saturn missions

Figures 3 to 4 show the variations in LEO mass for B coefficients of 0.01 and 0.1 . The variation in B coefficient would reflect the variation in the mass of the feed systems required for nuclear pulse unit storage, transfer, and ejection. Reference 26 noted that the B coefficient would likely be 0.01 . However, this mass could easily increase given the complexity of the feed systems and the need for multiple canisters to store the individual nuclear units. Each canister was designed to hold 100's of nuclear bomblet units.

For vehicles delivering a delta-V of $60 \mathrm{~km} / \mathrm{s}$, the LEO masses were 6,000 MT for the case of $\mathrm{B}=0.01$ to $7600 \mathrm{MT}$ for a $\mathrm{B}=0.10$. In many cases, space vehicles experience mass growth during development. As such, a more conservative mass estimate is always good for comparison. The vehicle masses for the highest delta-V cases are over 48,000 MT to 97,000 MT. These LEO masses are unusually high and will require many specialized heavy lift launch vehicles. Reference 30 noted the development of the NEXUS vehicle, a post Saturn V capability of over 450 MT (nearly 1 million lbm) into LEO. Reference 30 noted the need for a NEXUS launch capability of 4 to 8 times that of the Saturn V (implying up to nearly 1,000 MT into orbit). Certainly, high Isp options using fusion propulsion for the interplanetary vehicle would simplify operations and reduce the number of launches to LEO.

Even with an increase launch capability, the number of 1,000 MT payload launches required would likely be higher than 50. This number would also include cryogenic boiloff makeup (for propulsion, life support, science support, etc.), airborne support equipment, and other contingency masses.

\section{G. Atmospheric mining for Saturn mission refueling}

In order to reduce the LEO mass of the Saturn missions, atmospheric mining in the outer solar system (AMOSS) was investigated. Materials for the creation of NPP bomblets or physics packages (PPack) would be extracted and processed to refuel the Saturn vehicles for return to Earth. The AMOSS concept in the past has been rejected for Jupiter and Saturn. The extremely high atmospheric wind shear, the powerful atmospheric storms, and the intense radiation environments at Jupiter and Saturn make AMOSS operations very hazardous. In addition, the delta- $\mathrm{V}$ to attain orbit around these two planets for the atmospheric mining vehicles is extremely high, making the mining vehicles exceptionally large (Ref. 33).

The complexity of the orbit transfer from low Saturn orbit to an orbiting moon is another important issue. Atmospheric mining at Saturn was investigated with operations at 40 degrees north or 40 degrees south latitude. At these latitudes, the lowest wind speeds are prevalent. The wind speeds are more conducive to mining, and better survival of the mining aerospacecraft (ASC). The wind shear at the other latitudes would likely be destructive to any atmospheric vehicles.

Table VII compares the delta-V values for high thrust and low thrust OTV options. At Saturn, the delta-V for lifting the AMOSS fuel past the rings can be $29 \mathrm{~km} / \mathrm{s}$ (high thrust chemical $-14.5 \mathrm{~km} / \mathrm{s}$ one way, "likely" 
multiple stages required, a potential operational nightmare for recovery and reuse) to $94.4 \mathrm{~km} / \mathrm{s}$ (low thrust electric propulsion, including a 40 degree plane change at low Saturn orbit (which includes $26.6 \mathrm{~km} / \mathrm{s}$ for the 40 degree plane change in low Saturn orbit, $0.5 \mathrm{~km} / \mathrm{s}$ for ring particle avoidance, and $20.1 \mathrm{~km} / \mathrm{s}$ for low thrust electric propulsion orbital transfer for Titan, for a total of $47.2 \mathrm{~km} / \mathrm{s}$ for each one way transfer).

Figures 5, 6, and 7 present the round trip times, propellant masses, and the number of Titan lander flights for NEP vehicles for Saturn AMOSS. In figure 5, the trip time is shown for NEP vehicles delivering the $94.4 \mathrm{~km} / \mathrm{s}$ delta-V for the round trip mission - an $800 \mathrm{~km}$ altitude Saturn AMOSS rendezvous altitude to Titan and then return to the $800 \mathrm{~km}$ Saturn orbit. The minimum trip time for the $10 \mathrm{MWe}$ cases (with alpha $=10 \mathrm{~kg} / \mathrm{kW}$ ) was approximately 2,000 days. Figure 6 depicts the propellant mass for the NEP OTV. Figure 7 illustrates the number of lander flights required from Titan to resupply the NEP OTV with liquid hydrogen fuel. The $10 \mathrm{MWe}$ NEP vehicle (with alpha $=10 \mathrm{~kg} / \mathrm{kW}$ ) requires approximately 710 MT of hydrogen. Four 200 MT lander payload would be delivered for the NEP OTV refueling.

In comparison, based on the Ref. 33 calculations, the round trip low-thrust NEP delta-V for lifting the AMOSS derived atmospheric fuel (helium 3 and deuterium) from the top of the atmosphere to the moon base is approximately $31.5 \mathrm{~km} / \mathrm{s}$ (a worst case, for Neptune to Nereid, round trip) at either Uranus or Neptune. Titania was the moon selected for the Uranus system moon base. This OTV capability is much less demanding than that needed for Saturn AMOSS OTVs.

As noted in Table VII, for the orbital transfer delta-V values, there are 2 high thrust chemical or NTP propulsion options. One is a 2 burn transfer, with a high thrust transfer straight to Titan at $19.3 \mathrm{~km} / \mathrm{s}$, one way (a total delta- $\mathrm{V}$ for the sum of the elliptical orbit firing and the circularization firing). The 2 nd option uses a 3 burn transfer, first to $10^{\wedge} 8 \mathrm{~km}$ altitude (requiring $11.15 \mathrm{~km} / \mathrm{s}$ ), and a plane change at the high altitude (requiring a delta-V of $0.65 \mathrm{~km} / \mathrm{s}$ ). The final burn for descent to Titan's orbit requires $2.71 \mathrm{~km} / \mathrm{s}$. The total is $14.51 \mathrm{~km} / \mathrm{s}$. This delta-V does not included entering orbit about Titan. In general, the high thrust propulsion options are impractical, given the high delta- $\mathrm{V}$, the high initial ignition mass, and the unlikely possibility of reuse of a multi-staged vehicle,

The operations for using a multi-stage, reusable chemical propulsion system may become incredibly challenging and impractical. Having the stages deliver the required delta- $\mathrm{V}$ and then add additional delta- $\mathrm{V}$ and propellant for reuse will be a difficult challenge. Traffic control for recapturing, performing stage rendezvous, redocking (assembly of stages), and refueling the stages may be intractable. Also, there might be the need for 3, 4, or more stages.

\section{H. Uranus AMOSS -Uranus-Saturn-Uranus transportation flights}

As noted above, the complexity of AMOSS at Uranus is much lower than AMOSS for Saturn ISRU operations. Therefore, the idea of refueling a Saturn vehicle from Uranus was suggested. In the Uranus to Saturn option, the interplanetary transfer vehicle will have to deliver the AMOSS mined fuels from Titania (a likely Uranus moon base) to Titan (which would be a likely NPP vehicle staging area in orbit about Saturn). The interplanetary vehicle sizing will likely require $100 \mathrm{MWe}$ nuclear electric propulsion (NEP) vehicles, fueled from Titania (Uranus) resources. Once at Titan (Saturn), they can refuel there (or bring the complete round trip fuel load with it from Titania). The time for the delivery from Uranus to Saturn for several power levels is shown in Figure 8.

The nuclear fuels can be processed at the moon base factory into the physics packages (PPack), launched into Titania orbit and then transferred to the interplanetary transfer vehicle for the flight to Saturn. At Saturn, the 5,916 MT initial mass NPP vehicle delivers a $60 \mathrm{~km} / \mathrm{s}$ delta-V to return to Earth (see Figure 3). Approximately $5,200 \mathrm{MT}$ of propellant and tankage (tankage mass, computed using $\mathrm{B}=0.01 \mathrm{Mp}$ ) will be required for the NPP refueling. Based on past studies, the $100 \mathrm{MWe}$ NEP vehicle had a $200 \mathrm{MT}$ payload, and the initial mass was 2,000 MT (LEO to Neptune). If 5,200 MT must be delivered, then a minimum of 26 NEP flights are needed. Past analyses have shown that the packaging of payloads cannot be such an easily computed number, and thus approximately 30 flights will be needed to accomplish the payload delivery. 
Propulsion and mission analyses have shown that the Saturn NPP refueling with Saturn based AMOSS is impractical. The delta- $\mathrm{V}$ to transport the helium 3 from Saturn to Titan is very high and the (equatorial) high winds of the atmosphere make mining there difficult. Lower velocity winds are predicted and measured at 40 degrees $\mathrm{N}$ and 40 degrees $\mathrm{S}$ latitude. Therefore, after the ASC has mined the 3He, the OTV must effect a 40 degree plane change to return the mined fuel /propellant to an equatorial orbit for transfer to Titan. A high plane change delta-V for either low thrust or high thrust vehicles is a major stumbling block. However, NPP fuel can be imported from Uranus. This option seemed unlikely at the outset (based on the travel distance), however, analyses have shown that it is a practical option.

\section{Concluding Remarks}

Missions to Mercury and Saturn's moons are hopeful targets for future human missions. At Mercury, polar landing sites will offer important sources of water for soft landings and exploration missions. Using oxygen /hydrogen chemical propulsion and hydrogen powered NTP and ISRU, the water ice can provide capabilities to visit many locations on Mercury with refuelable landers. By refueling the 2 NTP return stages with hydrogen at Mercury, the interplanetary transfer vehicle LEO mass can be reduced from approximately 3,900 MT to 1,520 MT (for the Isp $=800$ seconds cases). At 850 seconds Isp, the LEO mass is reduced from approximately 2800 MT to 1140 MT.

With Saturn, powerful NPP vehicles were assessed. Round trip missions with very short trip times will require enormous masses in LEO: up to 48,000 MT with the most optimistic vehicle dry masses. More conservative vehicle tankage designs may require nearly 100,000 MT. Using ISRU for refueling of a one-way mission will reduce the LEO mass to approximately 6,000 MT to 8,000 MT. The most surprising result was the extreme added complexity of AMOSS at Saturn. As noted in previous research (BP AMOSS 2005, 2006), the orbital velocity at Saturn increases the mass of the ASC and the mass of the orbital transfer vehicles (OTV). The need to avoid the high wind speeds in the atmosphere leads to a large delta- $\mathrm{V}$ for large orbital plane changes which also increases the OTV mass.

\section{References}

${ }^{1}$ Ehricke, K. A., "Lunar industrialization and settlement - Birth of poly-global civilization," Lunar Bases and Space Activities of the 21st Century Conference, Houston, TX, Lunar and Planetary Institute, 1985, p. 827-855.

${ }^{2}$ Ehricke, K. A., "Harenodynamic cooling - The use of lunar sand as cooling medium," Acta Astronautica, Vol. 11, June 1984, p. 319-325.

${ }^{3}$ Ehricke, K. A., "Profitability of manufacturing in space in view of lunar industrial development and geo-socio-economic benefits," Manufacturing in space; Proceedings of the Winter Annual Meeting, Boston, MA, November 13-18, 1983, American Society of Mechanical Engineers, 1983, p. 183-198.

${ }^{4}$ Ehricke, K. A., “A socio-economic evaluation of the lunar environment and resources. III Selenospheric economics and cislunar/terrestrial market analysis," IAF PAPER 82-235, International Astronautical Federation, International Astronautical Congress, 33rd, Paris, France, Sept. 27-Oct. 2, 1982, $25 \mathrm{p}$.

${ }^{5}$ Ehricke, K. A., "A socio-economic evaluation of the lunar environment and resources. II Energy for the selenosphere," IAF PAPER 79-A-16, International Astronautical Federation, International Astronautical Congress, 30th, Munich, West Germany, Sept. 17-22, 1979, 25 p. 
${ }^{6}$ Krafft A. Ehricke, A socio-economic evaluation of the lunar environment and resources: I. Principles and overall system strategy," Acta Astronautica, Volume 8, Issues 11-12, NovemberDecember 1981, Pages 1389-1405.

${ }^{7}$ Ehricke, K., "Lunar industries and their value for the human environment on Earth." Acta Astronautica, 1974. Volume 1, pp. 585-622.

${ }^{8}$ Ehricke, K. "Further analyses of the slide lander and of drop delivery systems for improved lunar surface access," Acta Astronautica Volume 10, Number 9, pp. 629 to 650, 1983.

${ }^{9}$ Ehricke, K. A., "Economy of large launch vehicles including orbital labor cost," AIAA 1963277.

${ }^{10}$ Ehricke, K., "A comparison of propellants and working fluids for rocket propulsion," American Rocket Society (ARS) Journal, September-October 1953, Volume 23, Number 5, pp. 287-300.

${ }^{12}$ Manning, L. "Comparison of Several Trajectory Modes for Manned and Unmanned Missions to Mercury 1980-2000," AIAA 67-28, 1967.

${ }^{13}$ Marx, G., "Model study of fuel requirements for fast interplanetary flights using advanced nuclear propulsion systems and refueling at destination," Thesis, Technical University of Berlin (West Germany), In German, May 9, 1967.

${ }^{14}$ K. EHRICKE, "STUDY OF INTERPLANETARY MISSIONS TO MERCURY THROUGH SATURN WITH EMPHASIS ON MANNED MISSIONS TO VENUS AND MARS 1973/82 INVOLVING CAPTURE," Engineering Problems of Manned Interplanetary Exploration, 1963, AIAA 1963-1514.

${ }^{15}$ Ehricke, K., Perspective and Systems Engineering of Manned Planetary Flight," AAS 70-037, 1970. In: Space Shuttles and Interplanetary Flight, Volume 28, Advances in Astronautical Sciences, 1970.

\section{MESSENGER at Mercury:}

${ }^{16}$ David J. Lawrence et al., "Evidence for Water Ice Near Mercury's North Pole from MESSENGER Neutron Spectrometer Measurements.” Science 339, 292 (2013);

${ }^{17}$ Chabot, N., IMAGING INSIDE MERCURY'S PERMANENTLY SHADOWED CRATERS FIRST IMAGES FROM MESSENGER, Paper 1693, 44th Lunar and Planetary Science Conference (2013).

${ }^{18}$ David A. Paige, MESSENGER Planetary Conference Multimedia Page - MESSENGER Participating Scientist, University of California, Los Angeles, CA. http://messenger.jhuapl.edu/news_room/presscon12_multi.html . With: David A. Paige, et al., "Thermal Stability of Volatiles in the North Polar Region of Mercury," Science, January 18, 2013: Vol. 339, No. 6117, pp. 300-303.

Cassini at Saturn:

${ }^{19}$ G. TOBIE, J.I. LUNINE, J. MONTEUX, O. MOUSIS AND F. NIMMO, “The Origin and Evolution of Titan," in Titan: Interior, Surface, Atmosphere and Space Environment Muller-Wodarg, 
Griffith, Lellouch and Cravens, eds., Cambridge Univ. Press, pp. 24-50, 2012.

http://www.es.ucsc.edu/ fnimmo/website/Tobie_Titan.pdf .

${ }^{20}$ J.R. Spencer, F. Nimmo, "Enceladus: An active ice world in the Saturn System," Annual Review of Earth and Planetary Sciences 41, 693-717, 2013.

Mercury mission design:

${ }^{21}$ Christopher McLean, "Cryogenic Propellant Depots Design Concepts and Risk Reduction Activities," Future In-Space Operations (FISO), teleconference, March 2, 2011, 303-939-7133, cmclean@ball.com and http://spirit.as.utexas.edu/ fiso/archivelist.htm .

${ }^{22}$ MESSENGER - Mercury Orbit Insertion (MOI) Press Kit, NASA Headquarters and the Applied Physics Laboratory, Johns Hopkins University, March 2011, http://messenger.jhuapl.edu, http://messenger.jhuapl.edu/news_room/Mercury_PK_TST_Rev7_Web.pdf .

Titan:

${ }^{23}$ Fulchignoni, M., et al. "In situ measurements of the physical characteristics of Titan's environment” Nature 438, pp. 785-791, December 8, 2005.

Hopper:

${ }^{24}$ Linne, Diane L., Barsi, Stephen J., Sjauw En Wa, Waldy K., Landis, Geoffrey A., "Mars Surface Mobility Leading to Sustainable Exploration," AIAA Paper 2012-0806, January 2012.

Space vehicles:

${ }^{21}$ Palaszewski, B., "Metallized Propellants for the Human Exploration of Mars ," NASA-Lewis Research Center, NASA TP-3062, presented at the Case For Mars IV Conference, Boulder, CO, June 48 1990. Also in the AIAA Journal of Propulsion and Power, Vol. 8, No. 6, Nov.-Dec. 1992, pp. 11921199

${ }^{22}$ Bensky, M., "Propulsion requirements for soft landing in extraterrestrial environments," Rocketdyne, NAS7-124, NASA CR-55088, February 1963.

${ }^{23}$ Palaszewski, B., "Atmospheric Mining in the Outer Solar System: Resource Capturing, Storage, and Utilization," AIAA 2012-3742, July 2012.

${ }^{24}$ Palaszewski, B., "Atmospheric Mining in the Outer Solar System: Issues and Challenges for Mining Vehicle Propulsion,” AIAA 2011-6041, August 2011.

${ }^{25}$ Palaszewski, B., "Lunar Missions Using Advanced Chemical Propulsion: System Design Issues," NASA-Lewis Research Center, NASA TP-3065, AIAA 90-2341, presented at the 26th AIAA/ASME/SAE Joint Propulsion Conference, Orlando, FL, July, 1990, also in AIAA Journal of Spacecraft and Rockets, Vol. 31, No. 3, May-June 1994, pp. 458-465. 
Nuclear pulse propulsion:

695.

${ }^{26}$ Ehricke, K., "Interplanetary maneuvers in manned helionautical missions," (1965) AIAA 1965-

${ }^{27}$ Ehricke, K. A.," Solar Transportation," Presented to the 4th Goddard Memorial Symposium, AM. ASTRONAUTICAL SOC., WASHINGTON, D. C., 15-16 MAR. 1966

28 “A Grand Vision of Man's Role in Colonizing the Universe” by Oyang Teng, LaRouche Youth Movement (Book review) - Marsha Freeman, "Krafft Ehricke's Moon: The Extraterrestrial Imperative," Technology Editor of Executive Intelligence Review, 2009.

http://www.21stcenturysciencetech.com/Articles 2009/Summer-2009/Extraterrestrial Imperative.pdf

${ }^{29}$ G. R. Schmidt, J. A. Bonometti, and C. A. Irvine, "Project Orion and Future Prospects for Nuclear Pulse Propulsion,” JOURNAL OF PROPULSION AND POWER, Vol. 18, No. 3, May-June 2002.

${ }^{30}$ Krafft Ehricke, and FREEMAN D'VINCENT, "NEXUS - CONCEPT OF A LARGE REUSABLE LAUNCH VEHICLE,” AIAA 1963-277, 1963.

${ }^{31}$ Williams, Craig H.; Dudzinski, Leonard A.; Borowski, Stanley K.; Juhasz, Albert J., "Realizing "2001: A Space Odyssey": Piloted Spherical Torus Nuclear Fusion Propulsion," NASA/TM2005-213559, AIAA Paper 2001-3805, published 2005.

${ }^{32}$ Palaszewski, B., "Solar System Exploration Augmented by In-Situ Resource Utilization: Human Mercury and Saturn Exploration,” AIAA 2015-1654, January 2015.

${ }^{33}$ Palaszewski, B., "Atmospheric Mining in the Outer Solar System: Aerial Vehicle Mission and Design Issues, AIAA 2015-4078, July 2015

${ }^{34}$ Borowski, S., et al. "7-Launch" NTR Space Transportation Option for NASA's Mars Design Reference Architecture (DRA) 5.0, AIAA 2009-5308, July 2009. 


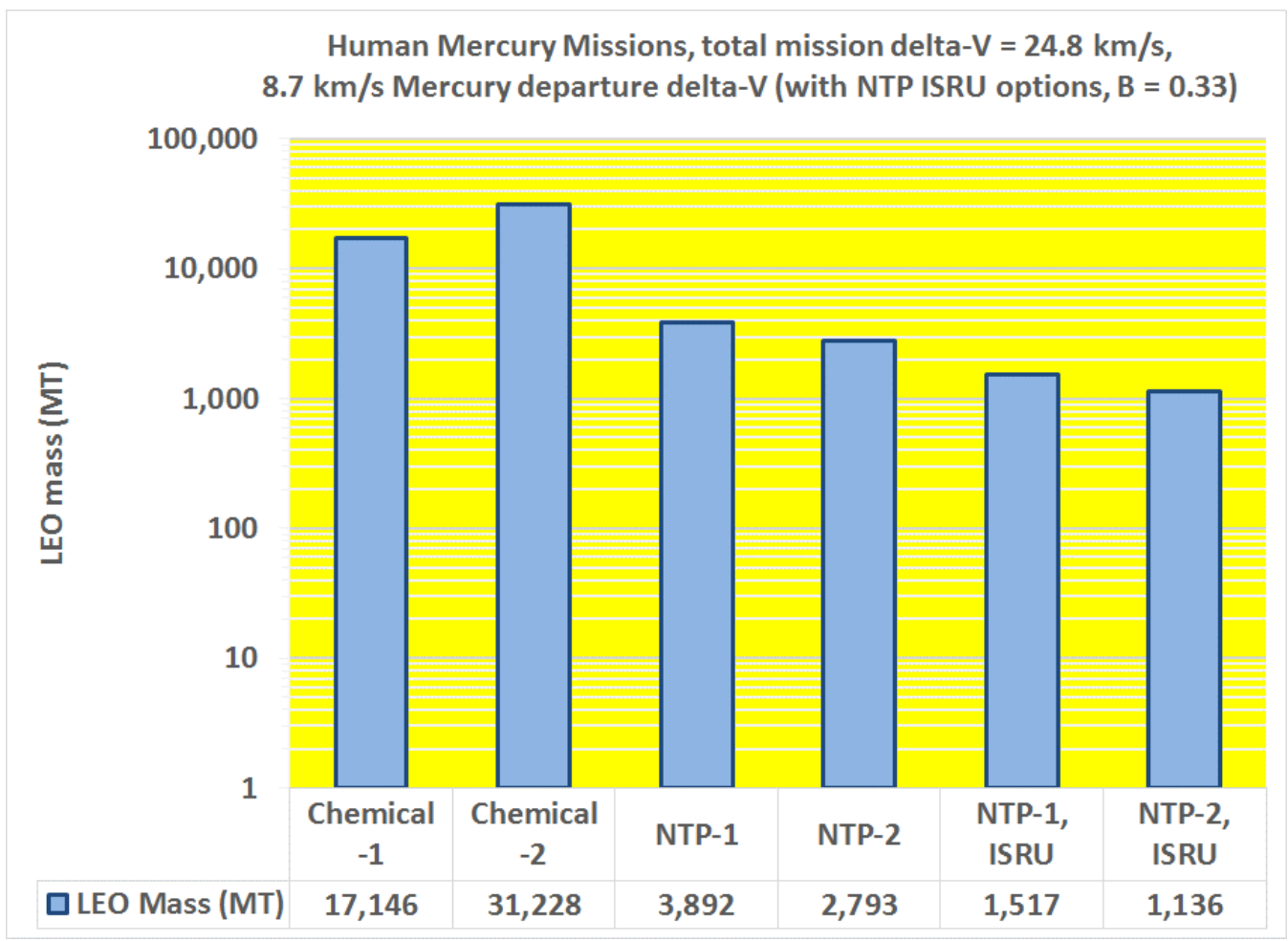

Figure 1. LEO masses for human Mercury mission

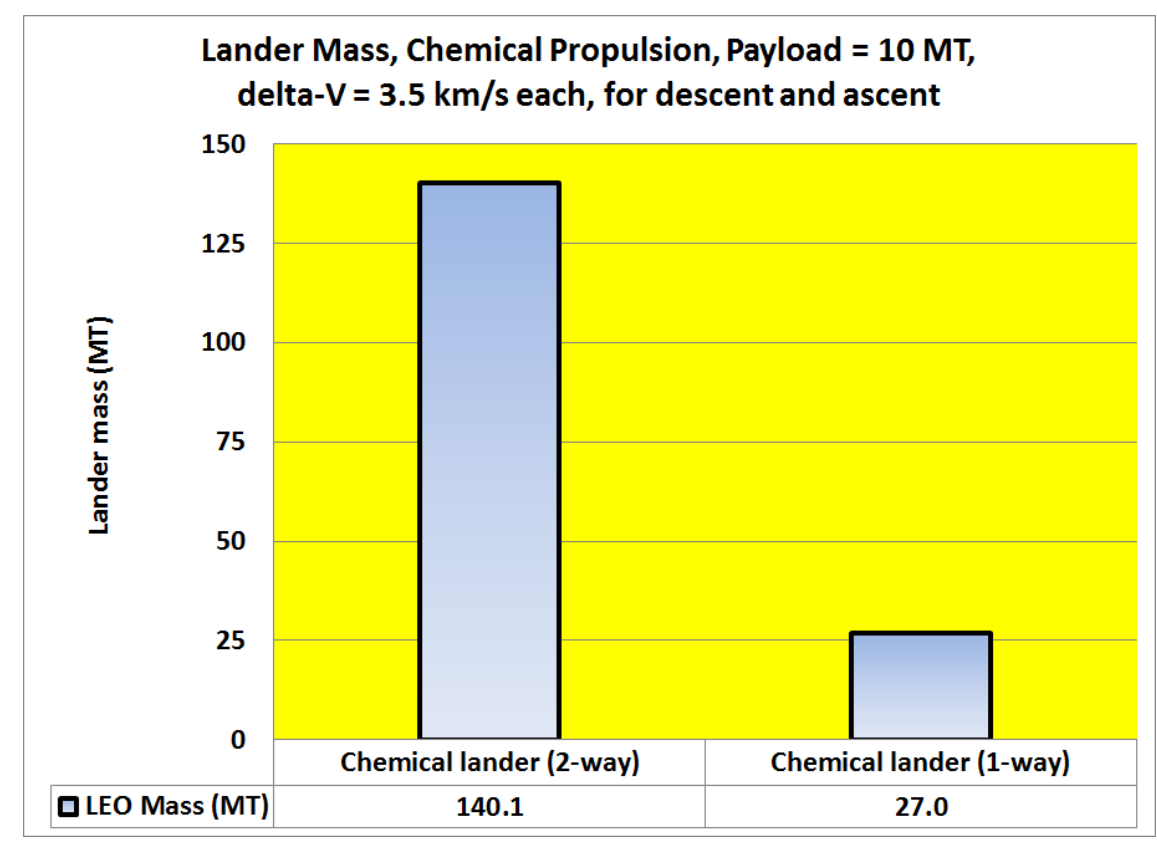

Figure 2. Mercury lander masses, 1 way and 2 way flights (Ref. 14). 
Table II: Propellant factory masses

AMOSS Propellant Factory sizing and masses Propellant factory for Mercury: The factory will take the raw materials from the outer planet moon's surface, lake(s), or ocean(s) and process them into oxygen and hydrogen for the chemical propulsion lander(s). Additional liquid hydrogen will also be produced as the fuel for the AMOSS OTVs (hydrogen MPD propulsion). Water may have to be processed from regolith or and liquid reservoir (lake(s), or ocean(s)).

\section{Subsystem list - overview:}

Factory machines.

Enclosures, protection against the elements, winds, micrometeoroids, etc.

Foundations for cryogenic surfaces (creating a stable structure for the base).

Buoyancy systems, if floating on cryogenic lakes, oceans, etc.

\section{Safety systems.}

Drilling systems (potentially deep drilling, for salt water oceans).

Melting - heating systems (for permafrost, cryogenic ices, extracting water from water ice-regolith mix, etc.).

Liquid feed systems.

Gaseous feed systems.

Liquefaction systems.

Liquid storage: cryogenic.

Liquid storage: non-cryogenic.

Gaseous storage.

And:

Liquid oxygen and liquid hydrogen storage.

Liquid oxygen and liquid hydrogen transfer to landers.

And:

Liquid hydrogen - Payload transportation to landers.

Liquid hydrogen - Payload loading onto landers.

Total (MT)

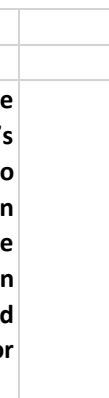

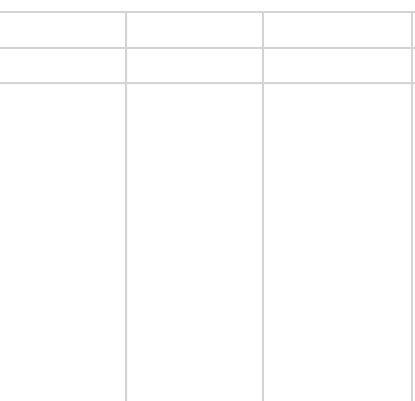

\begin{tabular}{l|l|l} 
Light & Heavy & Lightweight Super
\end{tabular}

Propellant Propellant Propellant Lightweight

factory. factory. factory, Propellant

propellants factory,

fed to propellants

lander and all fluids

tanks. fed to and

stored in

lander

tanks.

Mass, Mass, Mass, Mass,

estimated estimated estimated estimated

(MT)

(MT)

(MT)

(MT)

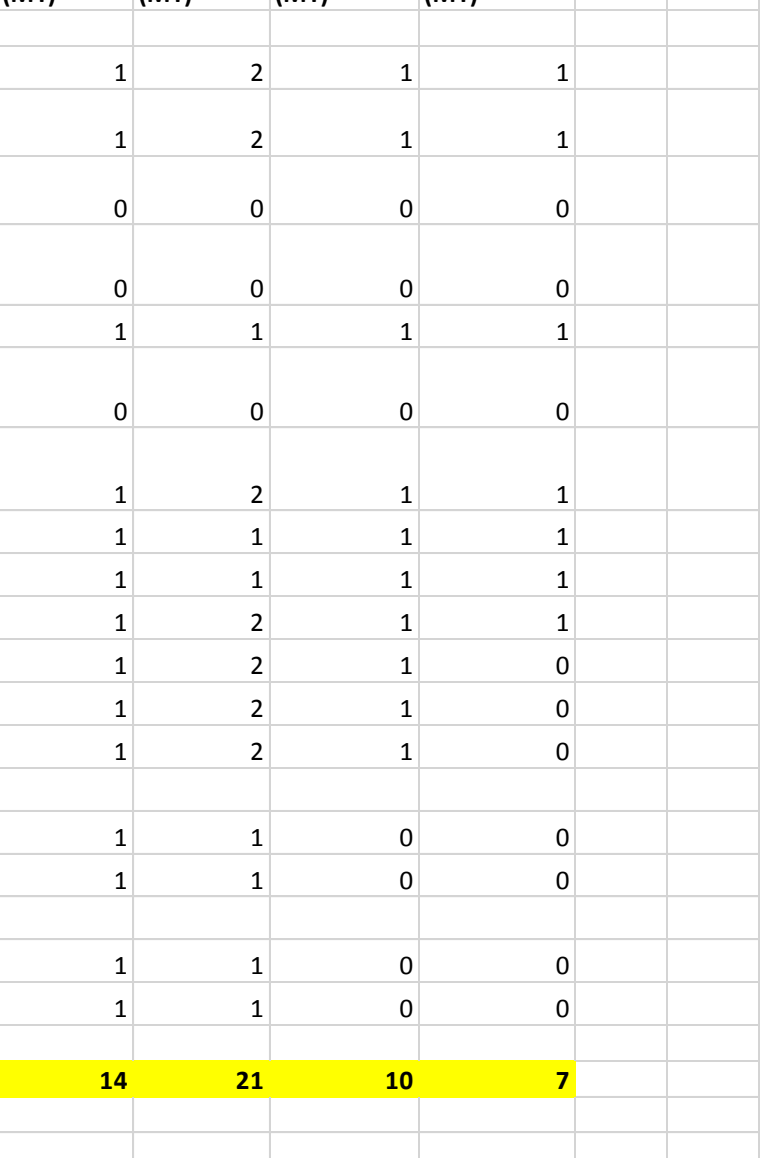


Table III: PPACK factory masses

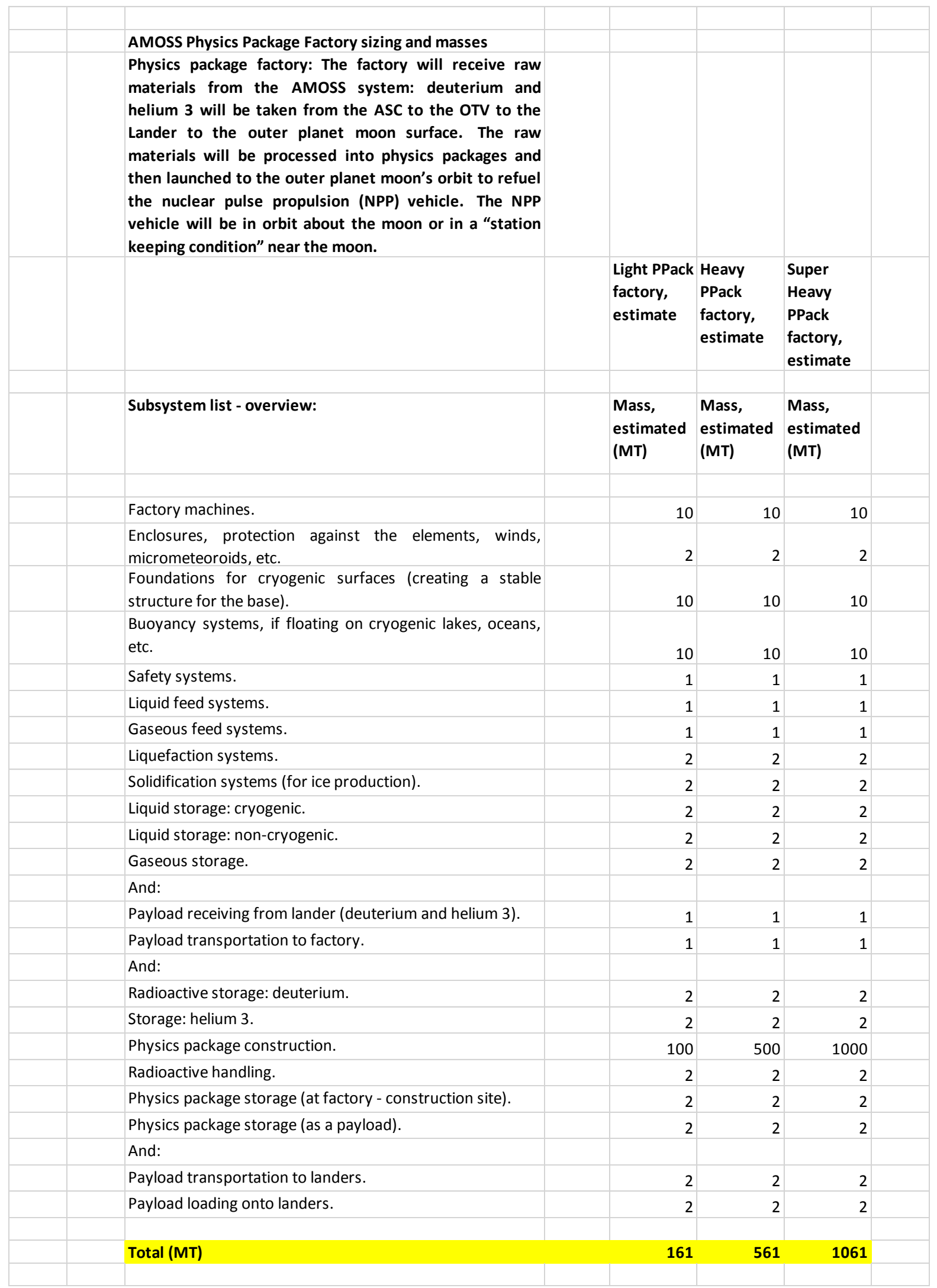


Table IV. NTP-1 mass summary (Isp = $800 \mathrm{~s}, \mathrm{~B}=0.33$ ), with no ISRU for any stage

\begin{tabular}{|c|c|c|c|c|c|c|}
\hline Parameter & $\begin{array}{l}\text { OTV } \\
\text { propellant } \\
\text { delivery, } \\
\text { Mercury } \\
\text { round trip }\end{array}$ & $\begin{array}{l}\text { OTV } \\
\text { propellant } \\
\text { delivery, } \\
\text { Mercury } \\
\text { round trip }\end{array}$ & $\begin{array}{l}\text { OTV } \\
\text { propellant } \\
\text { delivery, } \\
\text { Mercury } \\
\text { round trip }\end{array}$ & $\begin{array}{l}\text { OTV } \\
\text { propellant } \\
\text { delivery, } \\
\text { Mercury } \\
\text { round trip }\end{array}$ & $\begin{array}{l}\text { OTV } \\
\text { propellant } \\
\text { delivery, } \\
\text { Mercury } \\
\text { round trip }\end{array}$ & $\begin{array}{l}\text { OTV } \\
\text { propellant } \\
\text { delivery, } \\
\text { Mercury } \\
\text { round trip }\end{array}$ \\
\hline & NTP, H2 & NTP, H2 & NTP, $\mathrm{H} 2$ & NTP, H2 & NTP, $\mathrm{H} 2$ & NTP, $\mathrm{H} 2$ \\
\hline Delta-V (m/s) & $4,350.00$ & $4,350.00$ & $5,450.00$ & $5,450.00$ & $2,600.00$ & $2,600.00$ \\
\hline Isp (s) & 800.00 & 800.00 & 800.00 & 800.00 & 800.00 & 800.00 \\
\hline$G\left(\mathrm{~m} / \mathrm{s}^{\wedge} 2\right)$ & 9.81 & 9.81 & 9.81 & 9.81 & 9.81 & 9.81 \\
\hline & & & & & & \\
\hline Mdry fraction & 0.33 & 0.33 & 0.33 & 0.33 & 0.33 & 0.33 \\
\hline Mp/l (kg) & $31,970.00$ & $73,652.56$ & $169,680.95$ & $507,817.16$ & $1,519,783.27$ & $2,431,919.71$ \\
\hline & & & & & & \\
\hline ex & 1.74 & 1.74 & 2.00 & 2.00 & 1.39 & 1.39 \\
\hline $\mathrm{Mp}(\mathrm{kg})$ & $31,340.27$ & $72,201.79$ & $254,237.75$ & $760,876.77$ & $685,816.88$ & $1,097,427.26$ \\
\hline & & & & & & \\
\hline Mdry (kg) & $10,342.29$ & $23,826.59$ & $83,898.46$ & $251,089.34$ & $226,319.57$ & $362,151.00$ \\
\hline GLOW (kg) & $73,652.56$ & $169,680.95$ & $507,817.16$ & $1,519,783.27$ & $2,431,919.71$ & $3,891,497.97$ \\
\hline & & & & & & \\
\hline
\end{tabular}

Table V. NTP-1 mass summary (Isp = $800 \mathrm{~s}, \mathrm{~B}=0.33$ ), with ISRU at Mercury (hydrogen fueling of stages 5 and 6)

\begin{tabular}{|c|c|c|c|c|c|c|c|c|}
\hline Parameter & $\begin{array}{l}\text { OTV } \\
\text { propellant } \\
\text { delivery, } \\
\text { Mercury } \\
\text { round trip }\end{array}$ & $\begin{array}{l}\text { Stage } 6 \text { mass } \\
\text { elements }(\mathbf{k g})\end{array}$ & $\begin{array}{l}\text { Stage } 5 \text { mass } \\
\text { elements }(\mathrm{kg})\end{array}$ & $\begin{array}{l}\text { OTV } \\
\text { propellant } \\
\text { delivery, } \\
\text { Mercury } \\
\text { round trip }\end{array}$ & $\begin{array}{l}\text { OTV } \\
\text { propellant } \\
\text { delivery, } \\
\text { Mercury } \\
\text { round trip }\end{array}$ & $\begin{array}{l}\text { OTV } \\
\text { propellant } \\
\text { delivery, } \\
\text { Mercury } \\
\text { round trip }\end{array}$ & $\begin{array}{l}\text { OTV } \\
\text { propellant } \\
\text { delivery, } \\
\text { Mercury } \\
\text { round trip }\end{array}$ & $\begin{array}{l}\text { OTV } \\
\text { propellant } \\
\text { delivery, } \\
\text { Mercury } \\
\text { round trip }\end{array}$ \\
\hline & NTP, H2 & & & NTP, H2 & NTP, H2 & NTP, H2 & NTP, H2 & NTP, H2 \\
\hline Delta-V (m/s) & $4,350.00$ & & & $4,350.00$ & $5,450.00$ & $5,450.00$ & $2,600.00$ & $2,600.00$ \\
\hline Isp (s) & 800.00 & & & 800.00 & 800.00 & 800.00 & 800.00 & 800.00 \\
\hline$G\left(m / s^{\wedge} 2\right)$ & 9.81 & & & 9.81 & 9.81 & 9.81 & 9.81 & 9.81 \\
\hline & & & & & & & & \\
\hline Mdry fraction & 0.33 & & & 0.33 & 0.33 & 0.33 & 0.33 & 0.33 \\
\hline Mp/l (kg) & $66,138.88$ & & & $66,138.88$ & $66,138.88$ & $197,938.89$ & $592,386.87$ & $947,922.87$ \\
\hline & & & & & & & & \\
\hline ex & 1.74 & & & 1.74 & 2.00 & 2.00 & 1.39 & 1.39 \\
\hline Mp (kg) & 0.00 & $31,340.27$ & $72,201.79$ & 0.00 & $99,097.75$ & $296,577.43$ & $267,320.30$ & $427,759.35$ \\
\hline Mdry (kg) & 0.00 & $10,342.29$ & $23,826.59$ & 0.00 & $32,702.26$ & $97,870.55$ & $88,215.70$ & $141,160.59$ \\
\hline GLOW (kg) & $66,138.88$ & & & $66,138.88$ & $197,938.89$ & $592,386.87$ & $947,922.87$ & $1,516,842.80$ \\
\hline
\end{tabular}


Table VI. NTP-2 mass summary (Isp = $850 \mathrm{~s}, \mathrm{~B}=0.33$ ), with ISRU at Mercury (hydrogen fueling of stages 5 and 6 )

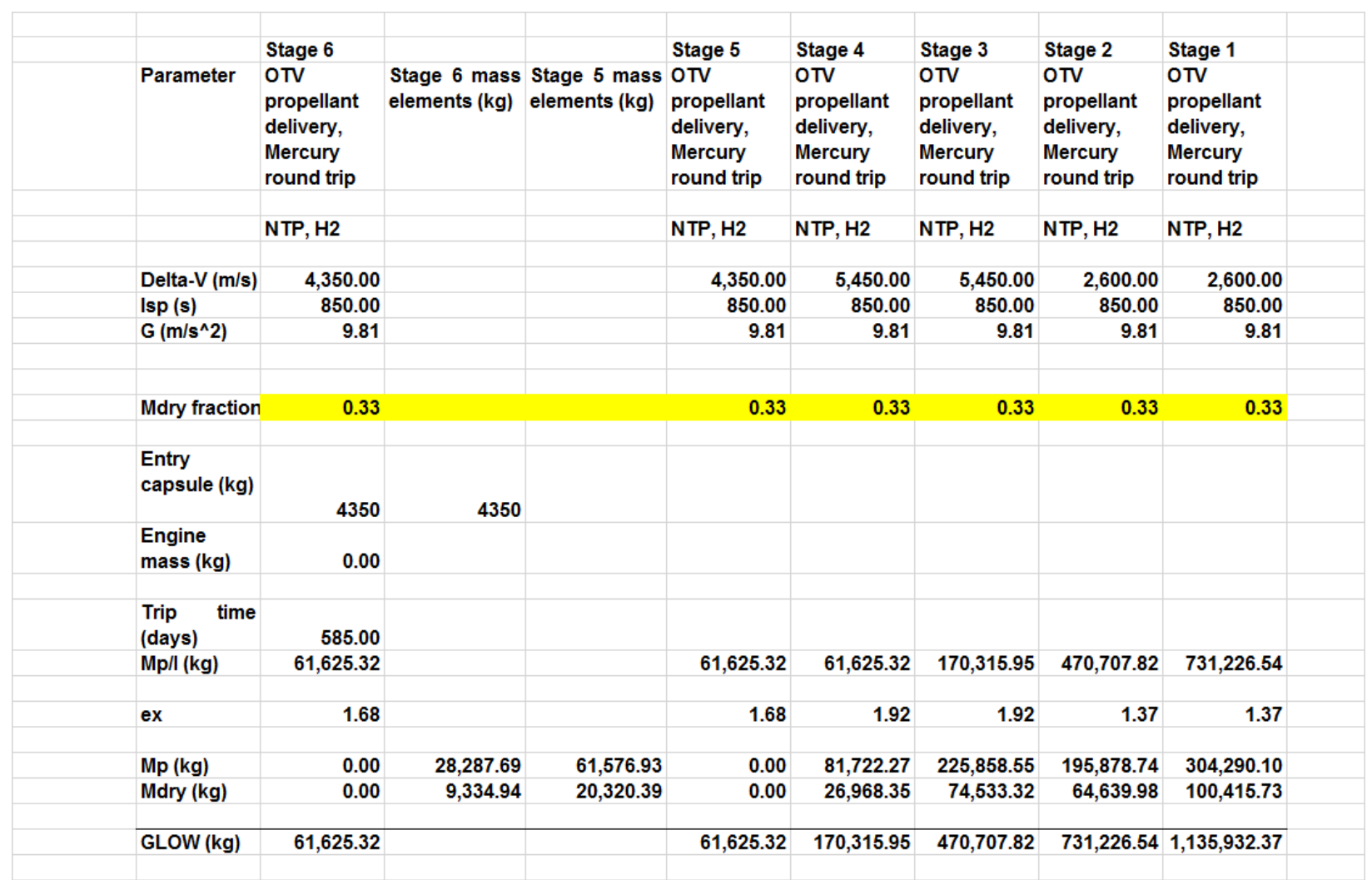

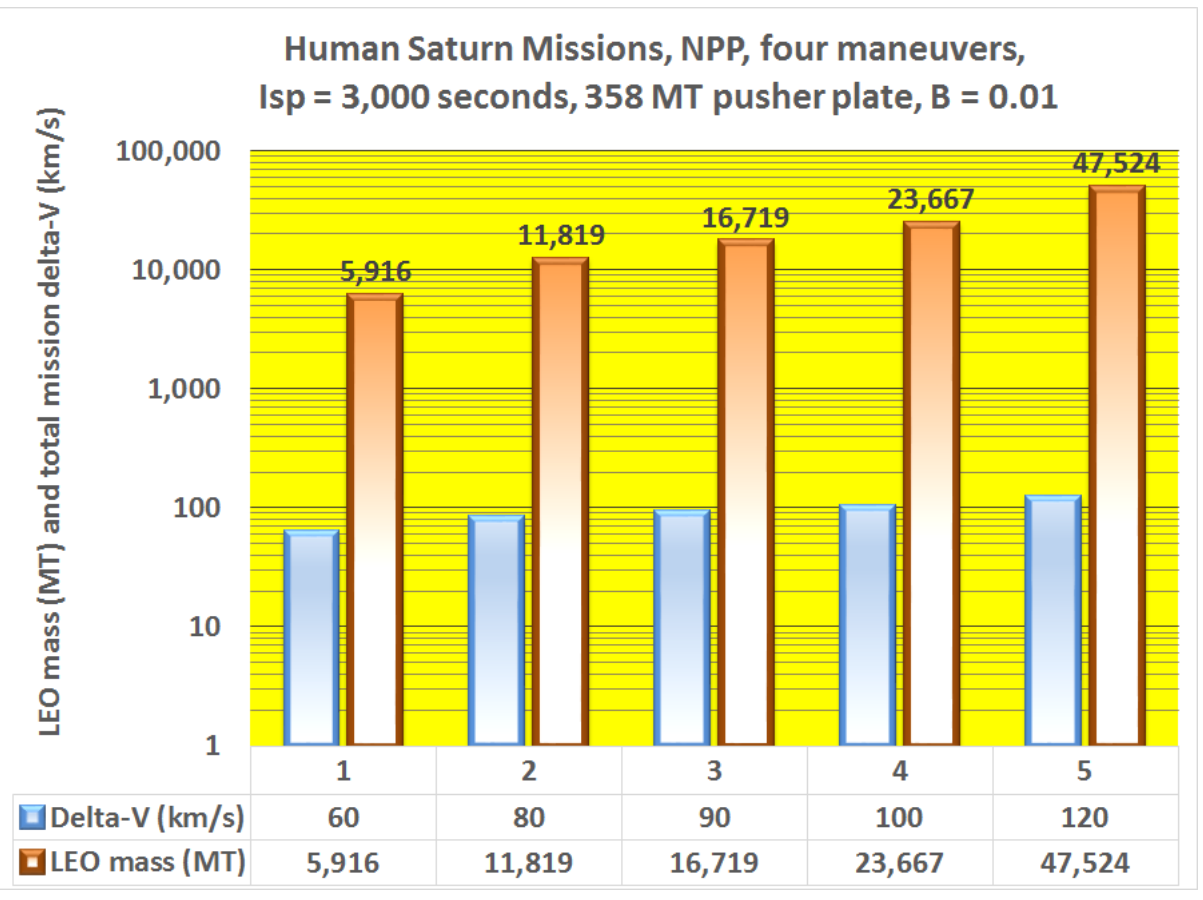

Figure 3. Saturn mission data, $\mathrm{B}=0.01 \mathrm{Mp}$ 


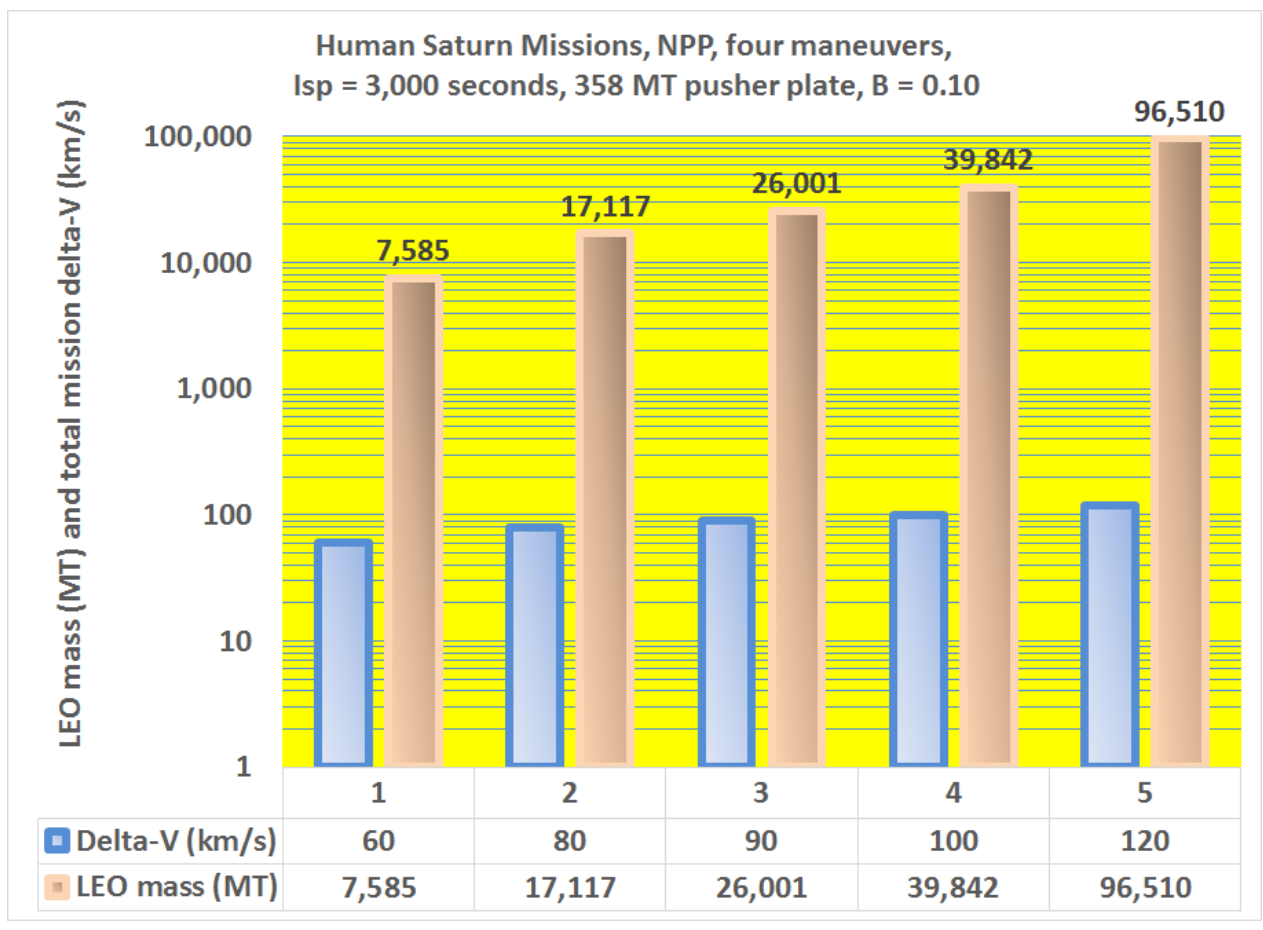

Figure 4. Saturn mission data, $\mathrm{B}=0.10 \mathrm{Mp}$

Table VII. One way delta-V values for AMOSS OTV flights

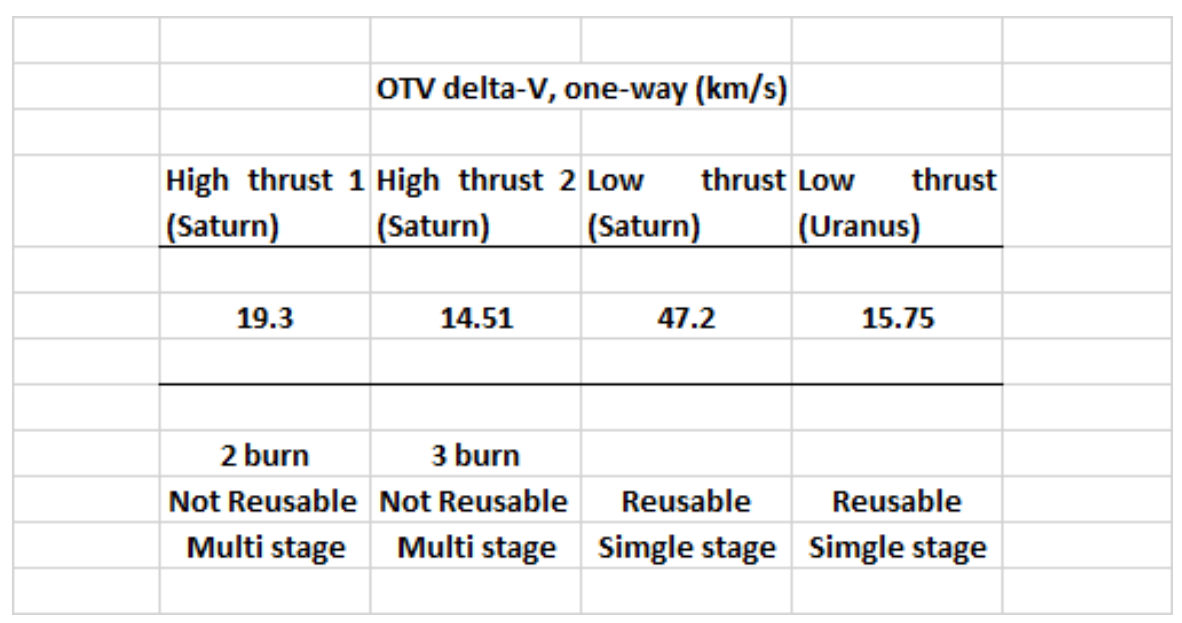




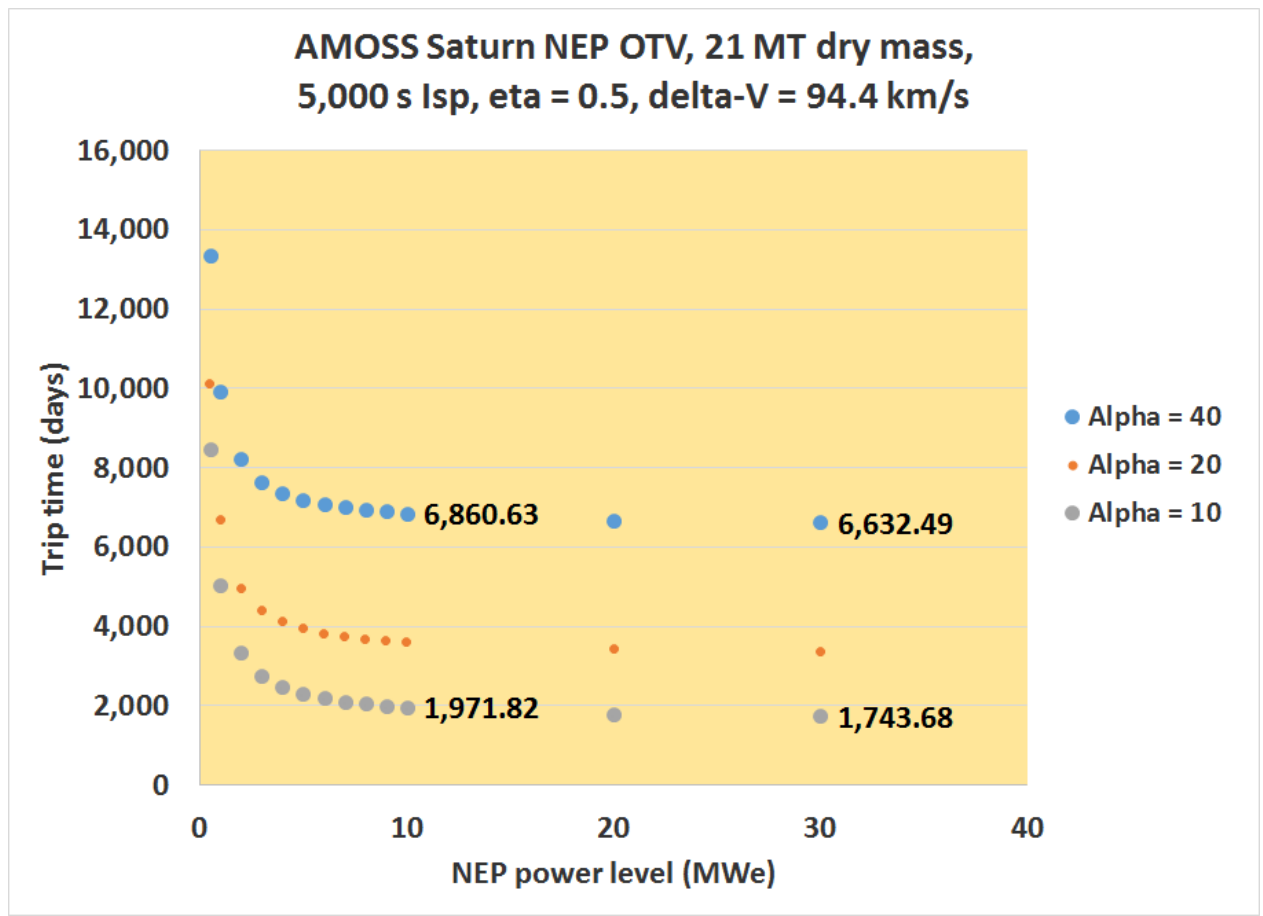

Figure 5. NEP trip time versus power level (cloud tops to Titan; round trip)

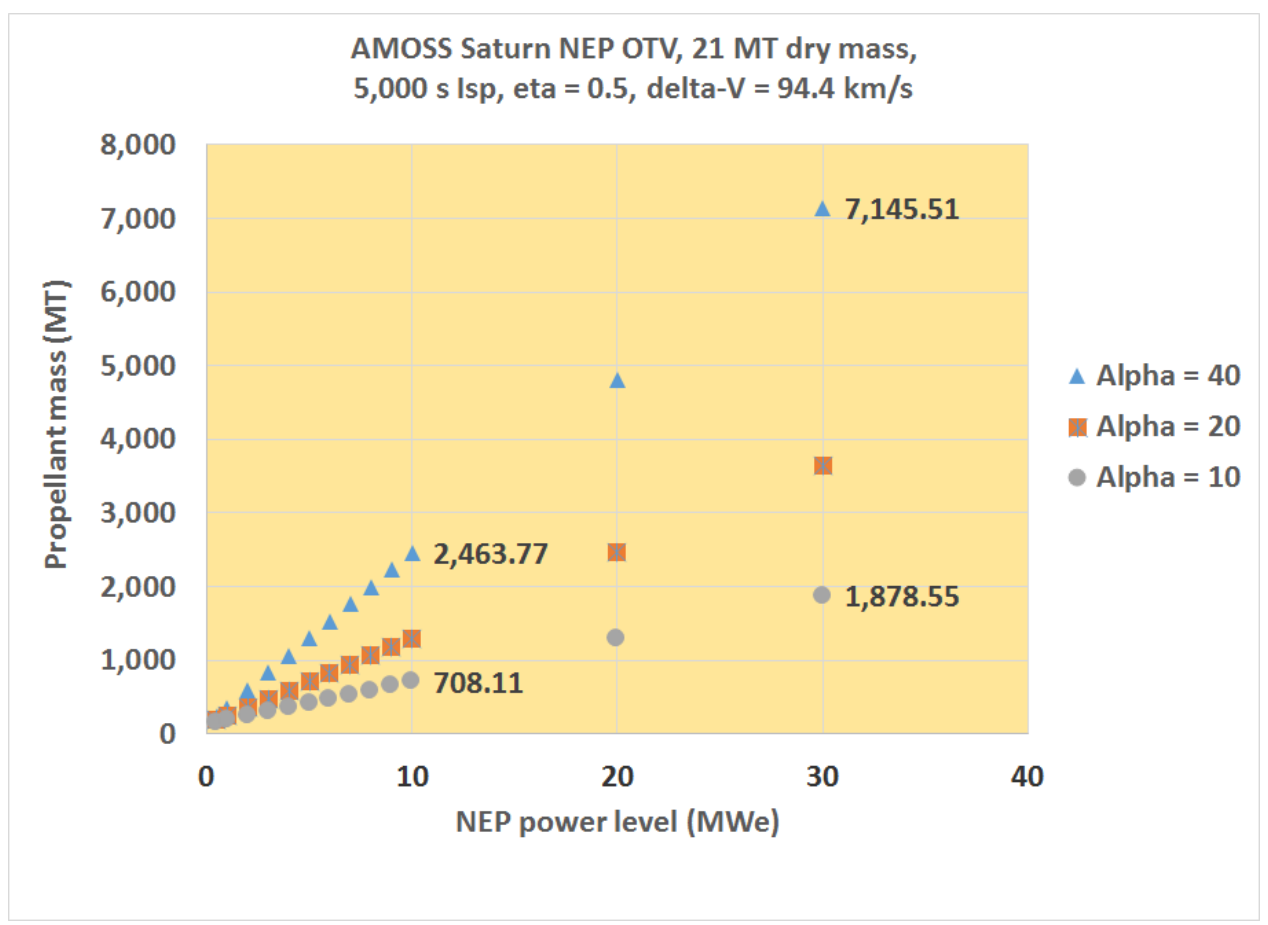

Figure 6. NEP propellant mass versus power level (cloud tops to Titan; round trip) 


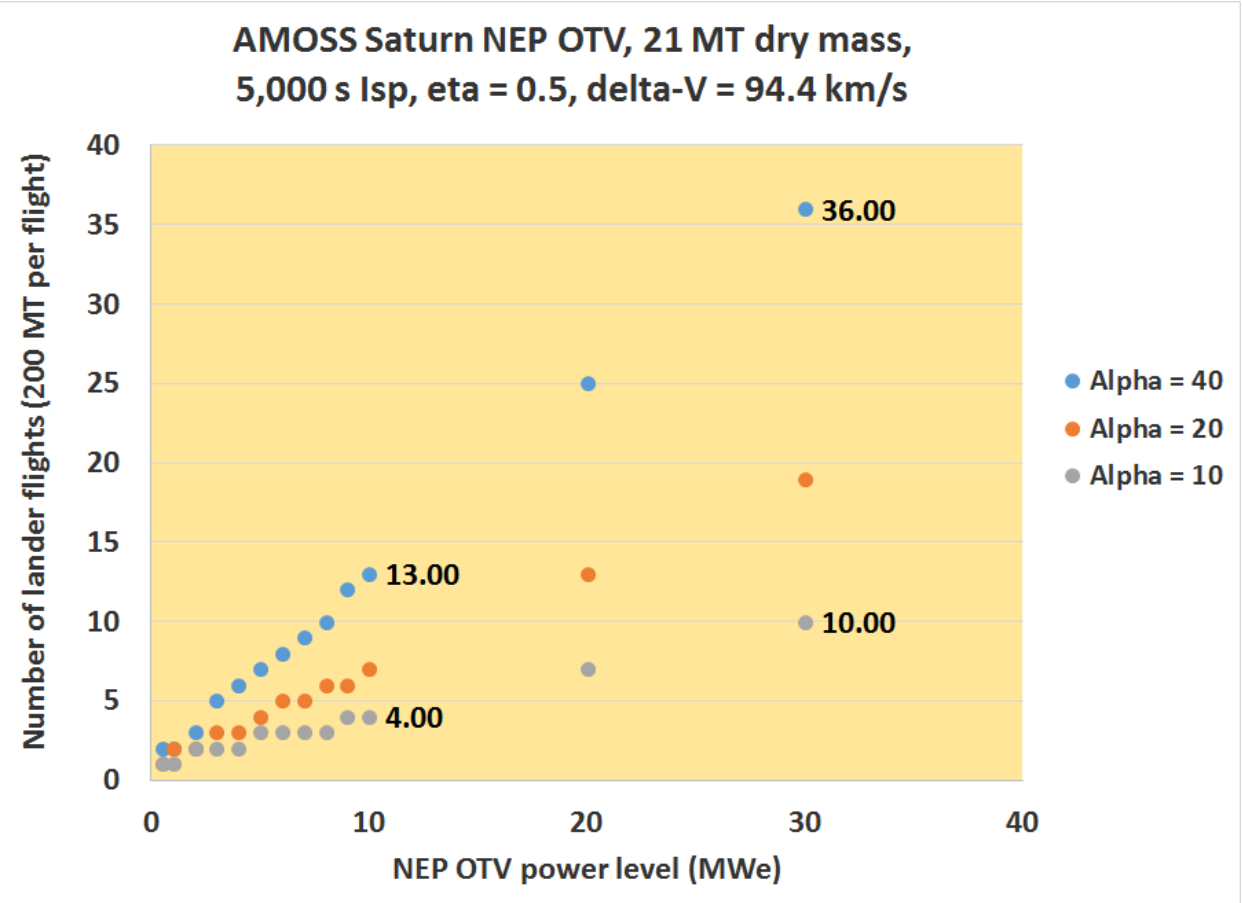

Figure 7. Number of lander flights for NEP refueling versus power level (cloud tops to Titan; round trip)

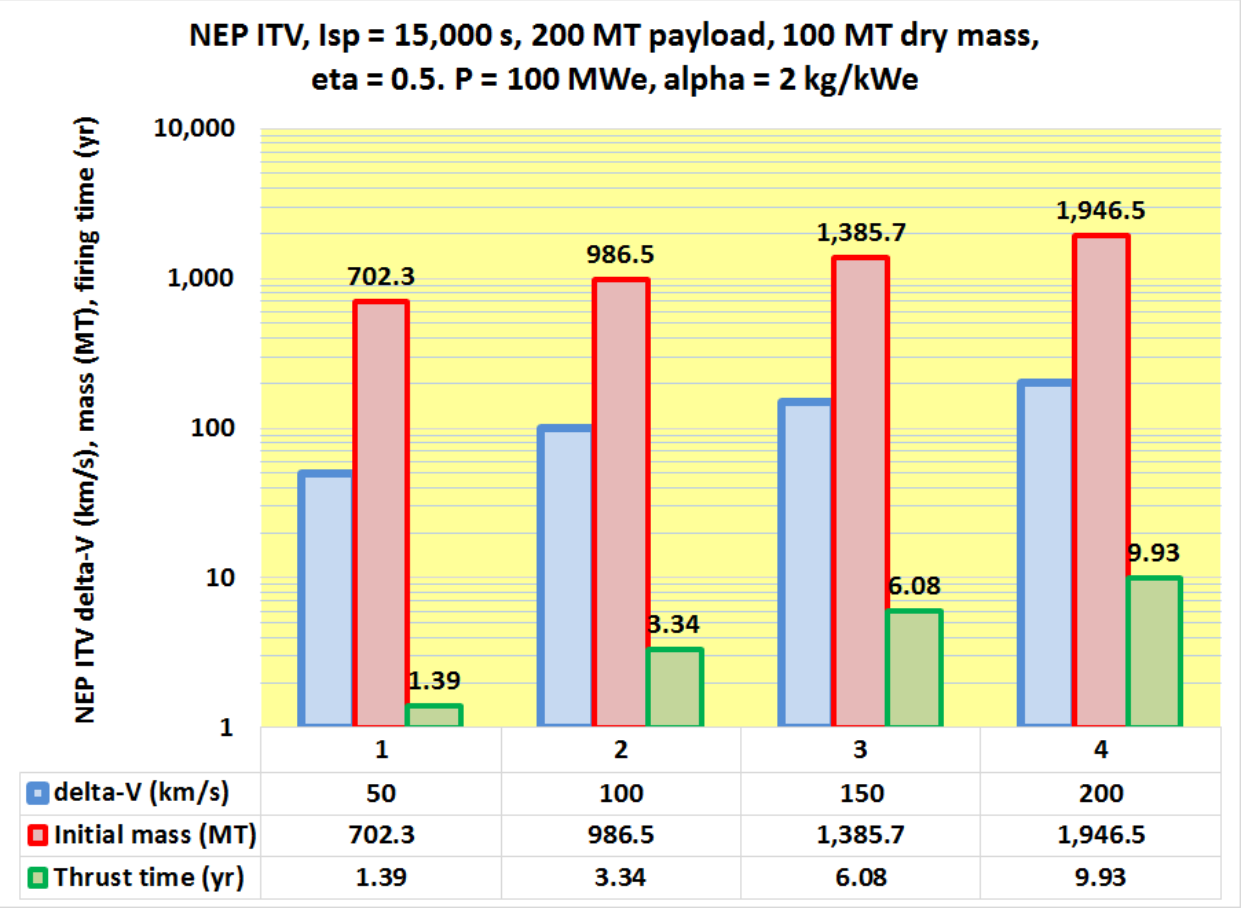

Figure 8. NEP ITV for carrying AMOSS fuels from Uranus to Saturn 


\section{Appendix A: Mission events - AMOSS}

Interplanetary delivery of AMOSS vehicle(s) to Saturn.

AMOSS vehicle(s) enter atmosphere and begin mining.

Interplanetary delivery of NPP bomblet factories.

Delivery of PPack factory to Titan vicinity (orbit, surface, etc.). PPack factory awaits raw materials.

Interplanetary delivery to OTVs for AMOSS - D, 3He - pickup and delivery of D, 3He to Titan PPack factory.

Interplanetary vehicles deliver landers for OTV propellant deliveries

Interplanetary vehicles deliver mining systems and/or propellant factories (on landers) for OTV propellant manufacturing.

The interplanetary delivery vehicles may be the OTVs (in some cases).

AMOSS vehicles perform atmospheric mining of $\mathrm{D}, 3 \mathrm{He}$.

OTVs rendezvous with AMOSS vehicles near the cloud tops (approximately an $800 \mathrm{~km}$ altitude).

OTVs transfer cryogenic gases from AMOSS vehicles to the OTVs. AMOSS ASC ascends to orbit, rendezvous with OTV, dock, and the 2 vehicles make the transfer.

OTVs deliver the cryogenic gases to Titan (moon) space.

Landers ascend from the moon, and rendezvous with the OTV, near the escape conditions for Titan.

Cryogenic gases (payloads) are transferred to the landers. 
Lander transfers hydrogen propellant to the NEP OTV.

Landers return to the Moon and transfer the payload to the PPack factory.

Propellant factory on the moon creates the oxygen and hydrogen for the landers propulsion.

Propellant factory also creates the hydrogen to refuel the OTV.

The OTV returns to the cloud tops to pick up another AMOSS payload. 